\title{
Echocardiography and Correction of Mitral Regurgitation: An Unbreakable Link
}

\author{
Sara Cimino ${ }^{a}$ Fabio Guarracino $^{b}$ Valentina Valenti ${ }^{e} f$ Giacomo Fratic, $d$ \\ Sebastiano Sciarrettac, ${ }^{c}$ Fabio Miraldi ${ }^{a}$ Luciano Agati $^{a} \quad$ Ernesto Greco $^{a}$ \\ ${ }^{a}$ Department of Cardiovascular, Respiratory, Nephrological, Anesthesiological, and Geriatric Sciences, Sapienza \\ University, Rome, Italy; ${ }^{b}$ Department or Anesthesia and Critical Care Medicine, Division of Cardiothoracic and \\ Vascular Anesthesia and Intensive Care, Azienda Ospedaliero Universitaria Pisana, Pisa, Italy; ' ${ }^{\text {Department of }}$ \\ Medico-Surgical Sciences and Biotechnologies, Sapienza University of Rome, Latina, Italy; ${ }^{d}$ RCCS Neuromed, Pozzilli,

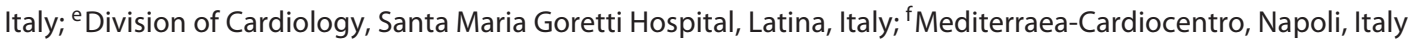

\section{Keywords}

Echocardiography $\cdot$ Mitral valve $\cdot$ Valve disease

\begin{abstract}
Background: Degenerative mitral valve (MV) disease causing mitral regurgitation (MR) is the most common organic valve pathology and is classified based on leaflet motion. MV repair is indicated as the preferred technique (Class I indication) when the results are expected to be durable. Therefore, a detailed and systematic evaluation of MV apparatus is pivotal in allowing the proper surgical planning, as well as the screening for trans catheter-based treatment when surgery is not indicated. Aim: The aim of the present review is to describe the crucial role of both Transthoracic Echocardiography (TTE) and Transesophageal Echocardiography (TEE) in the decisional process and the guidance of $M V$ repair procedures. TTE is the main investigation and the first approach used to make diagnosis of MR, to assess the severity and to describe the underlying mechanism, while TEE, especially with 3D echocardiography, has been shown
\end{abstract}

\section{KARGER}

(c) 2019 S. Karger AG, Basel

E-Mail karger@karger.com

www.karger.com/crd to be useful for clarifying complicated valvular anatomy, assessing the surgical result and detecting complications. The surgical treatment of MR takes advantage of ultrasound evaluation of MV apparatus at any stage of the process, thus making the link between surgery and echocardiography unbreakable throughout the perioperative phase.

(c) 2019 S. Karger AG, Basel

\section{Introduction}

Mitral regurgitation (MR) is the second most frequent indication for valve surgery in Europe. Its prevalence is increasing, despite the reduced incidence of rheumatic disease [1], probably due to heart failure and left ventricular dysfunction $[2,3]$. The normal function of the mitral valve (MV) depends on perfect interaction between all the components of its complex structure: the MV annulus, the leaflets, the sub-valvular apparatus (chordae tendinae, papillary muscles) and the left ventricle (LV) function and shape. Alterations in the leaflets or in other areas 
Fig. 1. MV Scallops in transthoracic echo (parasternal long axis and short axis view). A1-A2-A3 and P1-P2-P3: labels for MV Scallops. AO, aortic valve.
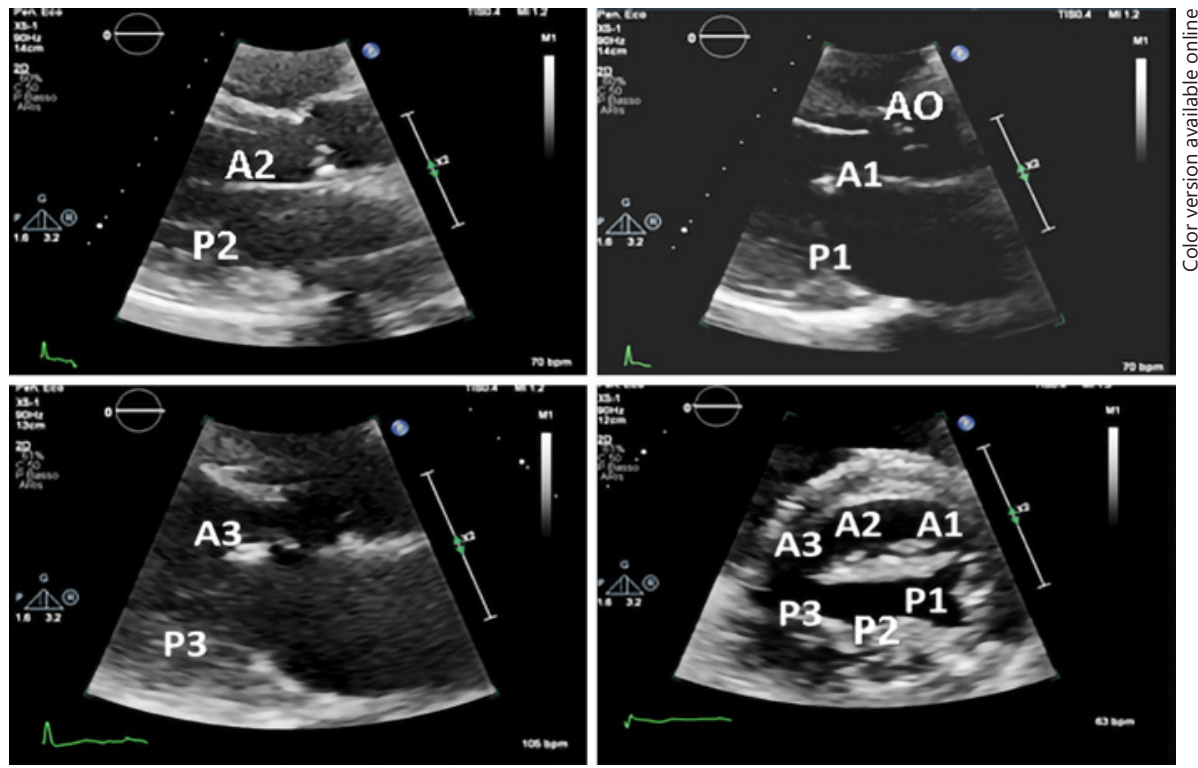

Table 1. Carpentier classification

\begin{tabular}{llll}
\hline Type & Leaflet's motion & Etiology & Primary/secondary \\
\hline I & Normal & Annulus dilation perforation & Primary \\
II & Excessive & Prolapse flail & Primary \\
& & Rupture papillary muscles & \\
IIIa & Restricted in systole and diastole & Rheumatic & Primary \\
IIIb & Restricted in systole & Tethering in cardiomyopathy & Secondary \\
\hline
\end{tabular}

of this structure may concur to MR development. The anatomical and functional defects can be addressed surgically, and the treatment options strongly depend on the mechanism of dysfunction. Therefore, a detailed and systematic evaluation of MV apparatus is pivotal in allowing the proper surgical planning, as well as the screening for trans-catheter-based treatment when surgery is not indicated. In this review, we aim at summarizing the most relevant and updated knowledge on perioperative echocardiography in MR treatment.

\section{Functional MV Anatomy and Implications for Surgery}

The MV is an asymmetric structure made of 2 leaflets: the posterior leaflet (PL) is the smaller one and is related to the $2 / 3 \mathrm{rd}$ of the annulus, while the anterior leaflet $(\mathrm{AL})$, covering the entire area of the $\mathrm{MV}$, is attached to the remaining $1 / 3 \mathrm{rd}$. The PL is divided into 3 scallops (P1-P2$\mathrm{P} 3$ ) and the AL can be divided as well into 3 virtual scallops
(A1-A2-A3), matching PL ones. A1 and P1 are in correspondence of the anterolateral commissure, close to the left atrial appendage, while A3 and P3 are in correspondence of the posteromedial commissure, close to the tricuspid annulus, as showed in Figure 1. According to the etiology, MR can be classified as primary (organic or intrinsic valve disease) or secondary (functional, without evidence of leaflet disease). Causes of primary MR include more frequently degenerative disease (Myxoid degenerative disease, Barlow, Fibro-elastic deficiency), but also rheumatic disease or endocarditis. Causes of secondary MR include all the conditions in which the LV dilates losing its elliptical shape and the papillary muscles are displaced (ischemic heart disease, dilated cardiomyopathy). To note, ruptured papillary muscle secondary to acute myocardial infarction, is classified as a primary ischemic MR [4]. Carpentier classification is related to leaflet's motion and is useful to describe the different mechanisms responsible of MR [5]. Type I includes MR with normal leaflet's motion (e.g., due to annulus dilation or leaflet perforation). Type II includes 
MR with excessive leaflet's motion (Prolapse or Flail due to chordal elongation or rupture); Type IIIa includes MR with restrictive leaflet motion in both systole and diastole (rheumatic valve) and Type IIIb, MR with restrictive leaflet motion in systole (tethering during LV remodeling), as shown in Table 1. Current ESC Guidelines [6] recommend surgery for severe chronic primary MR in symptomatic patients or asymptomatic with LV dysfunction (LV enlargement or reduced ejection fraction), taking also into account the presence of atrial fibrillation (AF) due to the risk of embolic events (47) or pulmonary hypertension (PH). Flail of valve leaflets due to chordal rupture is an indication to surgical correction even in absence of strict criteria. MV repair is indicated as the preferred technique (Class I indication) when the results are expected to be durable. A different technique of mitral repair has been described following 2 major schools: Resect or Respect techniques: using the classic "French correction" by A. Carpentier or using of Neo-Chordae implantation. Mitral annuloplasty is used in almost all patients in whom leaflet resection is performed, to stabilize the repair and to restore the size and the shape of the valve. A Sliding or Folding technique is recommended if PLs is too high $(>2 \mathrm{~cm})$ to avoid postoperative systolic anterior movement (SAM). In patients with secondary severe MR, surgery is strongly recommended only if the patient has also an indication for coronary artery bypass grafting or other valve pathologies. The superior use of mitral replacement in this setting has been demonstrated by recent reports showing a high incidence of early reappearance of regurgitation after conservative surgery. MV replacement in this setting is today more accepted than previously. Percutaneous edge-to-edge MV repair with MitraClip system is indicated in both primary and secondary severe MR, for patients inoperable or at high surgical risk, who are symptomatic despite optimal medical therapy and cardiac resynchronization therapy when indicated [7]. Moreover, the intervention is indicated only in the presence of specific echocardiographic criteria of eligibility [8]. Before surgery it is also important to have a high quality imaging of the MV. The latter is necessary for a better characterization of the factors involved in valve diseases and also in understanding the severity of mitral regurgitation.

\section{Transthoracic Echocardiography}

Transthoracic Echocardiography (TTE) is the main investigation used to make diagnosis of MR, to assess the severity, and to describe the underlying mechanism. The contextual assessment of global LV and right ventricle (RV) function, pulmonary circulation and left atrium (LA) dimensions (associated with AF) provides additional information to predict short and long-term outcome after surgery $[9,10]$ and to establish the likelihood of repair. Current Guidelines [6] consider the presence of AF and $\mathrm{PH}$ grade as adjunctive factors to take into account for surgery.

\section{Left Chamber Quantification}

TTE has the main role to assess LV dimension and function: LV dysfunction could be the cause of a secondary $\mathrm{MR}$, but it is also important to evaluate consequences of a primary MR on the LV, subjected to a chronic volume overload. Current Guidelines [11] recommend both 2D (Simpson method) and 3D echocardiography for LV volumes and left ventricular ejection fraction quantification. Real-time 3D echocardiography is recommended when the acoustic window is adequate because the analysis of a full volume acquisition can provide a more reliable and reproducible quantification of LV volumes and function [12]. LA enlargement is a consequence of chronic MR. Patients with a small LA are less likely to have a high grade of MR. LA volume should be measured by $2 \mathrm{D}$ echocardiography, with biplane assessment of end-systolic LA measurements [11]. More recently, a new fully automated algorithm was developed to quantify LA and LV volumes and left ventricular ejection fraction from 3D TTE without human interaction. This new echo algorithm shows excellent correlation with magnetic resonance imaging and with high reproducibility $[13,14]$.

\section{$R V$, Tricuspid Regurgitation and $P H$}

Chronic MR causes persisting elevated pressure in the LA and consequent post-capillary $\mathrm{PH}$. $\mathrm{PH}$ is related to $\mathrm{RV}$ and right atrium enlargement and RV dysfunction [11]. In the evaluation of patients with significant MR, it is also mandatory to assess the amount of tricuspid regurgitation (TR) and to measure the tricuspid annulus. It is already demonstrated $[15,16]$ that the pre-surgical tricuspid annulus measurement predicts residual functional TR post MV surgery. This pre-surgical evaluation is mandatory to assess if a concomitant tricuspid annuloplasty ring is necessary at the time of MV surgery. Tricuspid valve surgery is currently recommended for patients with severe TR undergoing left-sided valve surgery, irrespective of symptoms (Class I) and should be considered (Class IIa) in patients with mild/moderate secondary TR and/or significant annular dilatation $(\geq 40$ $\mathrm{mm}$ or $21 \mathrm{~mm} / \mathrm{m}^{2}$; Class IIa) [6]. Intraoperative measure 
of tricuspid ring $>70 \mathrm{~mm}$ may also be used to indicate annuloplasty. Despite the complete assessment of RV dimension and function being achievable only by $3 \mathrm{D}$ Echocardiography or CMR, in clinical practice, the most used method to assess RV dilatation is by measurements RV areas (both end-diastolic and end-systolic area) and linear dimensions in end-diastole (basal and mid-cavity). Basal diameter $>42 \mathrm{~mm}$, mid-cavity diameter $>33 \mathrm{~mm}$ indicate RV enlargement [17]. Visual assessment of RV function is usually derived from the geometric evaluation of inter-ventricular septum movement in systole and diastole, which may change in the presence of pressure/volume overload. The fractional area change is the percentage change of RV chamber area during the entire cardiac cycle measured from the apical 4-chamber view; a fractional area change of $>35 \%$ is considered a normal value [17]. Tricuspid annular plane systolic excursion assesses the degree of tricuspid annular displacement toward the apex and accurately reflects RV longitudinal function. Current guidelines recommend the use of tricuspid annular plane systolic excursion $(<15 \mathrm{~mm})$, tricuspid annular systolic TDI velocity $(<11 \mathrm{~cm} / \mathrm{s})$, and RV end-systolic area $\left(>20 \mathrm{~cm}^{2}\right)$ to identify patients with RV dysfunction [17].

\section{Diastolic Dysfunction}

In the presence of significant MR, diastolic function is impossible to assess because of the over-estimation of trans-mitral E wave velocity, which is usually high $(>1.2$ $\mathrm{m} / \mathrm{s})$. Patients with severe MR are less likely to have E/A ratio $<1$; this finding could be helpful in severity assessment of MR. Pulmonary veins Pulsed Wave Doppler can show a reversal flow on $S$ wave in case of severe MR [4].

\section{Assessment and MR Quantification}

Role of pre-surgical echocardiography is to provide a precise anatomical description of the MV lesions, according to Carpentier Classification, to assess the feasibility of $\mathrm{MV}$ repair and to help the surgeon to a proper valve correction. TTE can provide an initial overview of the valve and the sub-valvular apparatus and their anatomical characteristics (e.g., the presence of billowing of the leaflets, or prolapse, or chordal rupture). The exam should start from parasternal long axis view, which allows the 2D measurement of MV annulus (diastolic), with a good visualization of A2-P2 scallops [4]. Starting from this view it is possible to visualize also A1-P1 and A3-P3 tilting the probe respectively toward the aortic valve and the tricuspid valve, as showed in Figure 1. Basal short axis view allows the measurement of MV planimetric area. In the 3-chambers apical view, scallops identification is more difficult, and their localization is similar to the correspondent transesophageal views (see transesophageal section). The origin and the direction of the regurgitant flow, visualized by Color-Doppler, could be helpful to understand the mechanisms of MR; for example, Type II MR are more likely to be eccentric, with a jet direction that is opposite to the prolapsing leaflet. MR severity quantification should be performed as recommended by the current Guidelines [6]. Proximal Iso-velocity Surface Area assessment could be not reliable in presence of multiple or eccentric regurgitant jets and in most cases, a multiparametric approach is mandatory.

\section{Exercise Echocardiography}

Exercise echocardiography is suggested by current Guidelines [4] to quantify exercise-induced changes in MR and the increment of pulmonary artery systolic pressure with the evaluation of contractile reserve of the LV. The absence of contractile reserve could identify patients at increased risk of cardiovascular events. Exercise echocardiography may also be helpful to unmask unclear symptoms. The presence of symptoms, especially in association with a quick pulmonary artery systolic pressure increase at early stages of exercise, should be considered in the decision-making process of surgical treatment.

\section{Transesophageal Echocardiography}

In patients with severe MR requiring surgery, multiplane transesophageal echocardiogram (TEE) is necessary before surgery. TTE is diagnostic in most cases, but TEE is recommended, particularly in presence of suboptimal TTE image quality. In the specific, TEE may help to identify the mechanisms contributing to MV disease and to define the specific site responsible for MV dysfunction, with higher sensitivity than TTE alone.

\section{$2 D$ TEE}

Multiplane 2D TEE allows the visualization of all MV with a segmental analysis of the scallops in different views. 2D TEE can identify the diseased scallops by performing a detailed, multiplane assessment [17]. At $0^{\circ}$ in midesophageal view (4-chamber view) is possible to visualize $\mathrm{A} 2-\mathrm{P} 2$, in 5-chamber view A1-P1 and in downward 4-chamber view A3-P3. This view is also useful to assess the measurement of tricuspid annulus in TEE. In bi-commissural view it is possible to visualize $\mathrm{P} 1-\mathrm{A} 2-\mathrm{P} 3$. Starting from bi-commissural view, with a counter clock rotation 
Fig. 2. MV Scallops in transesophageal echo (4 chamber view, bicommissural view and LVOT view). A1-A2-A3 and P1-P2P3: labels for MV Scallops. TEE, transesophageal echocardiogram.
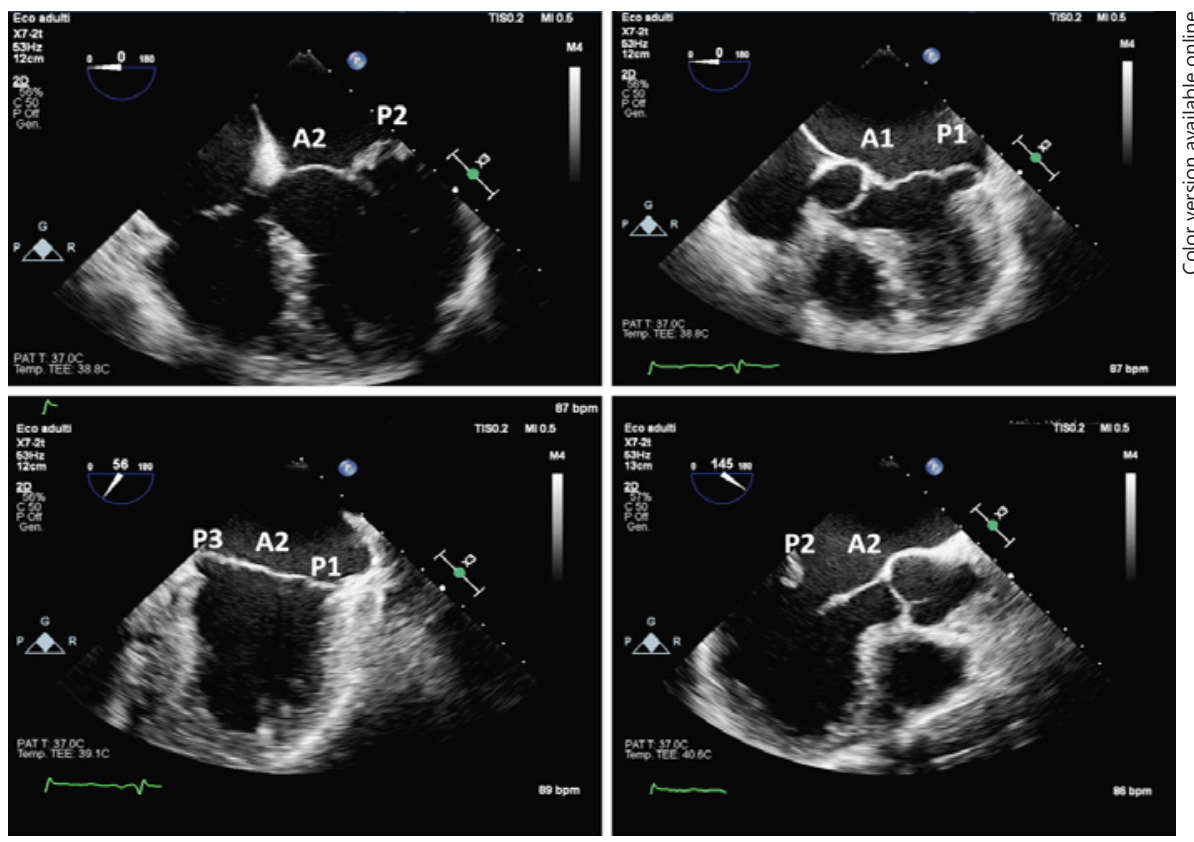

of the probe is possible to visualize A1-P1 (and the anterolateral commissure), while with a clock wise rotation of the probe is possible to visualize A3-P3 (and the posteromedial commissure). At $120^{\circ}$ (LVOT view), it is possible to visualize A2-P2, as showed in Figure 2. In transgastric view at $0^{\circ}$ it is possible to visualize all scallops and to obtain MV planimetric area. Severity quantification of MR should be performed as recommended by guidelines [6].

\section{D TEE}

An exhaustive TEE in a patient with complex MV anatomy requires great experience and skill [18-20]. In some cases, a Multiplane 2D TEE may lead to an inaccurate evaluation of the scallops. On the other hand, 3DTEE may provide a comprehensive visualization of the different components of MV apparatus, overcoming several weaknesses of a 2D multiplane TEE [21-23]. In addition, 3D TEE is particularly useful in the dialogue between echo-cardiographer and surgeon, providing an "en-face" view seen from the LA perspective of the MV [24], which is identical to the surgical view in the operating room, as showed in Figure 3. This view allows, for example, to better analyze the extent of commissural fusion in rheumatic MR or commissural prolapse in degenerative disease, the leaflet and scallops involved in degenerative myxomatous disease and the associated presence of chordal rupture or prolapse of different scallops; or the differential diagnosis between "indentation" and "cleft"

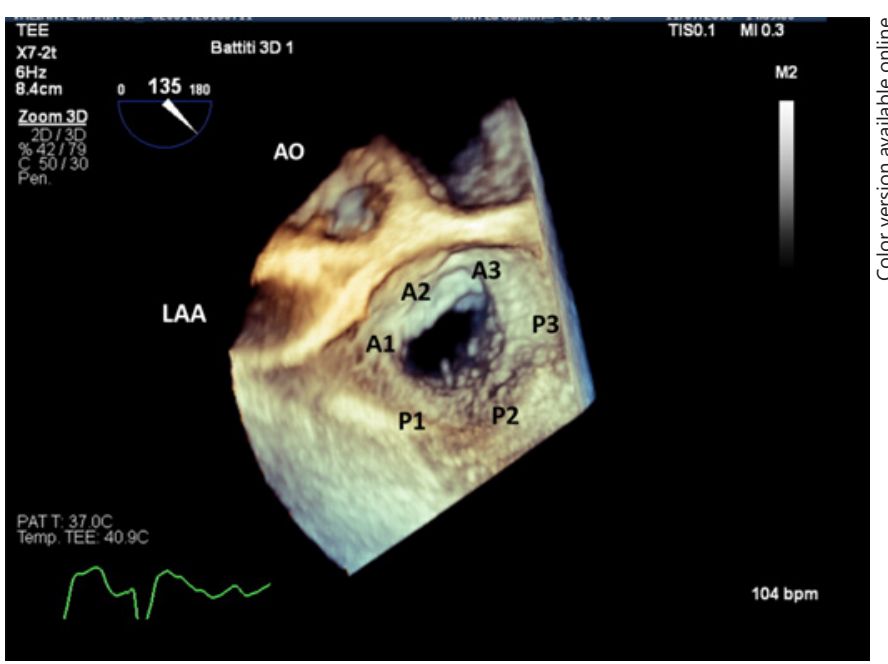

Fig. 3. MV Anatomy (3D Real time echocardiography). A1-A2-A3 and P1-P2-P3: labels for MV Scallops. AO, aortic valve; LAA, left atrial appendage; TEE, transesophageal echocardiogram.

[25]. A proper preoperative analysis is mandatory to perform a correct repair of the MV. Intra-procedural analysis of the result with inspection or hydrostatic maneuvers can be unable to detect marginal prolapse of secondary scallops affecting long-term results of surgery; 3D TEE images can be post-processed offline with software for MV quantification. This rendering reconstruction of the MV allows reliable measurements of MV annulus, area, tenting area, mitral-aortic angle and PL angle [26]. 3D 
Table 2. Unfavorable characteristics for MV repair

Unfavorable characteristics for repair

MV characteristics $\quad$ Features of valve abnormalities

Primary $M R$

Regurgitant jet

Central, large

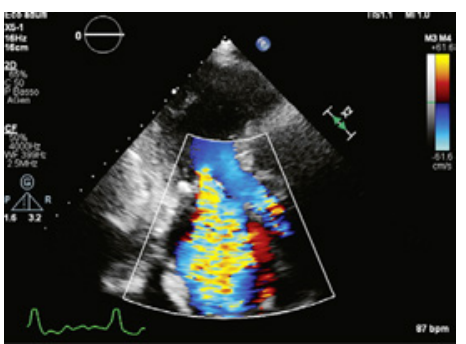

\begin{tabular}{ll}
\hline Valve calcification & +++ \\
\hline Annulus dilation & +++
\end{tabular}

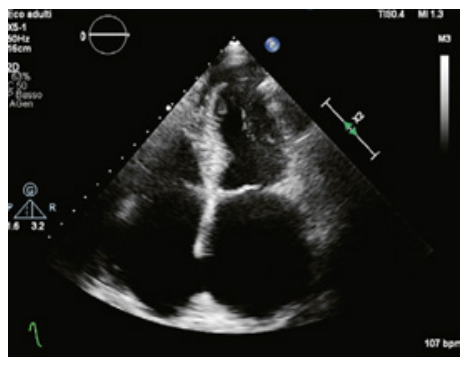

Prolapsing scallops

$>3$

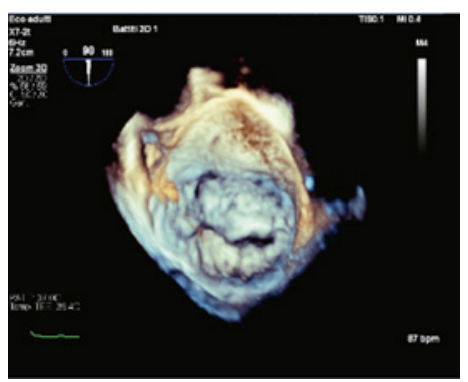

\begin{tabular}{ll}
\hline $\mathrm{AL}$ & Large (risk of SAM) \\
\hline $\mathrm{LV}$ & Small cavity (risk of SAM)
\end{tabular}

Secondary $M R$

Regurgitant jet Severe

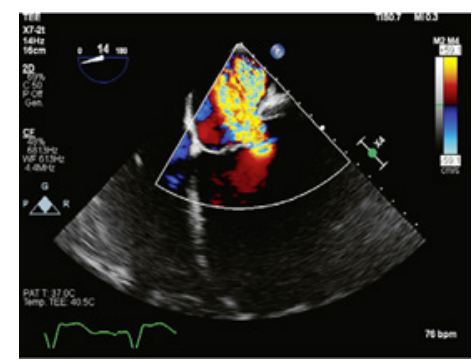

\begin{tabular}{ll}
\hline Annulus dilation & $>37 \mathrm{~mm}$ \\
\hline Coaptation distance & $>1 \mathrm{~cm}$ \\
\hline Tenting area & $>2.5 \mathrm{~cm}^{2}$ \\
\hline PL leaflet angle & $>45^{\circ}$ \\
\hline
\end{tabular}


Table 2 (continued)

Unfavorable characteristics for repair

MV characteristics Features of valve abnormalities

LV dilation Severe

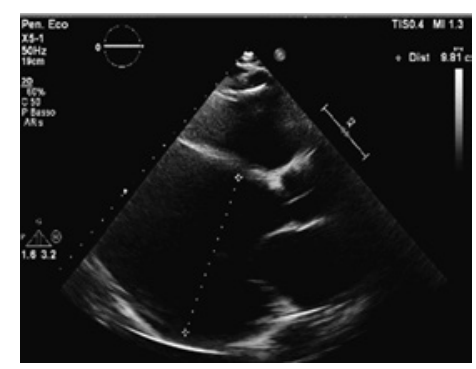

MR, mitral regurgitation; SAM, systolic anterior movement; LV, left ventricle; MV, mitral valve; PL, postero-lateral; AL, anterior leaflet.

TEE is not an alternative to multiplane 2D TEE, is a complementary technique, which allows obtaining additional information to help the surgeon.

\section{TEE Pre-Surgical Evaluation}

Several echocardiographic parameters can be helpful to identify patients at risk of treatment failure. In primary $\mathrm{MR}$, the presence of a large central regurgitant jet, severe annular dilatation ( $>50 \mathrm{~mm}$ ), involvement of $\geq 3$ scallops [27] and extensive valve calcification are associated with MV repair failure. Moreover, lack of valve tissue is also an important predictor of unsuccessful repair both in rheumatic valve disease and in patients who have had infective endocarditis with valve perforation. It is also important to measure the coaptation-septum distance, the mitralaortic angle, the high of PLs and ratio between anterior and PLs that are all determinants of postoperative SAM of MV, which can lead to hemodynamic instability [28]. Risk factors for SAM are the presence of a long AL and a non-dilated hyper-dynamic LV. Moreover, the AL height at A2 (middle scallop) helps to select the appropriate ring size [29].

Regarding secondary MR, repair is usually offered in ischemic etiology at the time of surgical revascularization and consists mainly of undersized annuloplasty [30-32]. The more LV is dilated, the more difficult is MV repair with frequent recurrence of regurgitation in $<2$ years. The presence of severe regurgitant jet associated with an MV annulus diameter $\geq 37 \mathrm{~mm}$, a coaptation distance $>1 \mathrm{~cm}$, a systolic tenting area $>2.5 \mathrm{~cm}^{2}$, a PL leaflet angle $>45^{\circ}$ and the presence of asymmetric tethering [33] are related with high probability of treatment failure. All pa- rameters are summarized in Table 2 . Today there is a trend in the setting of functional mitral regurgitation to prefer MV replacement when surgery is required. Moreover, the presence of a severe LV dilation increases the risk of MV repair failure and is associated with low likelihood of reverse LV remodeling after repair and poor late outcome [26].

\section{Role of Echocardiography during Minimally Invasive Mitral Surgery}

Minimally invasive and video-assisted mitral surgery reached a growing interest in the last 10 years allowing an improved recovery after operation through a small surgical access and avoiding median sternotomy, eluding some postoperative complication like infection or blood lost. Due to a very small access to the heart $(<5 \mathrm{~cm})$, the use of TEE is crucial for a proper "view" by surgeon of cardiac structures [34-38]. Echo images are mandatory during cannulas insertion in femoral vessels for Cardiopulmonary bypass using Seldinger technique. An accurate view of guide wire during advancement of cannulas is crucial in avoiding complication, like vessels damage, and in order to place the cannula in right position into cardiac chambers. Through a bi-caval view of the right atrium, a correct position for the venous drainage is possible avoiding dislocation of the tip of the cannula to the inter-atrial septum. When intra-aortic occlusion of ascending aorta is used (Port-Access Technique), TEE allows a safe and effective introduction over guide-wire and positioning of Endoclamp through the entire thoracic and abdominal aorta with short and long axis view. Before Endoclamp inflation, in order to reach a comfortable and safe stabili- 


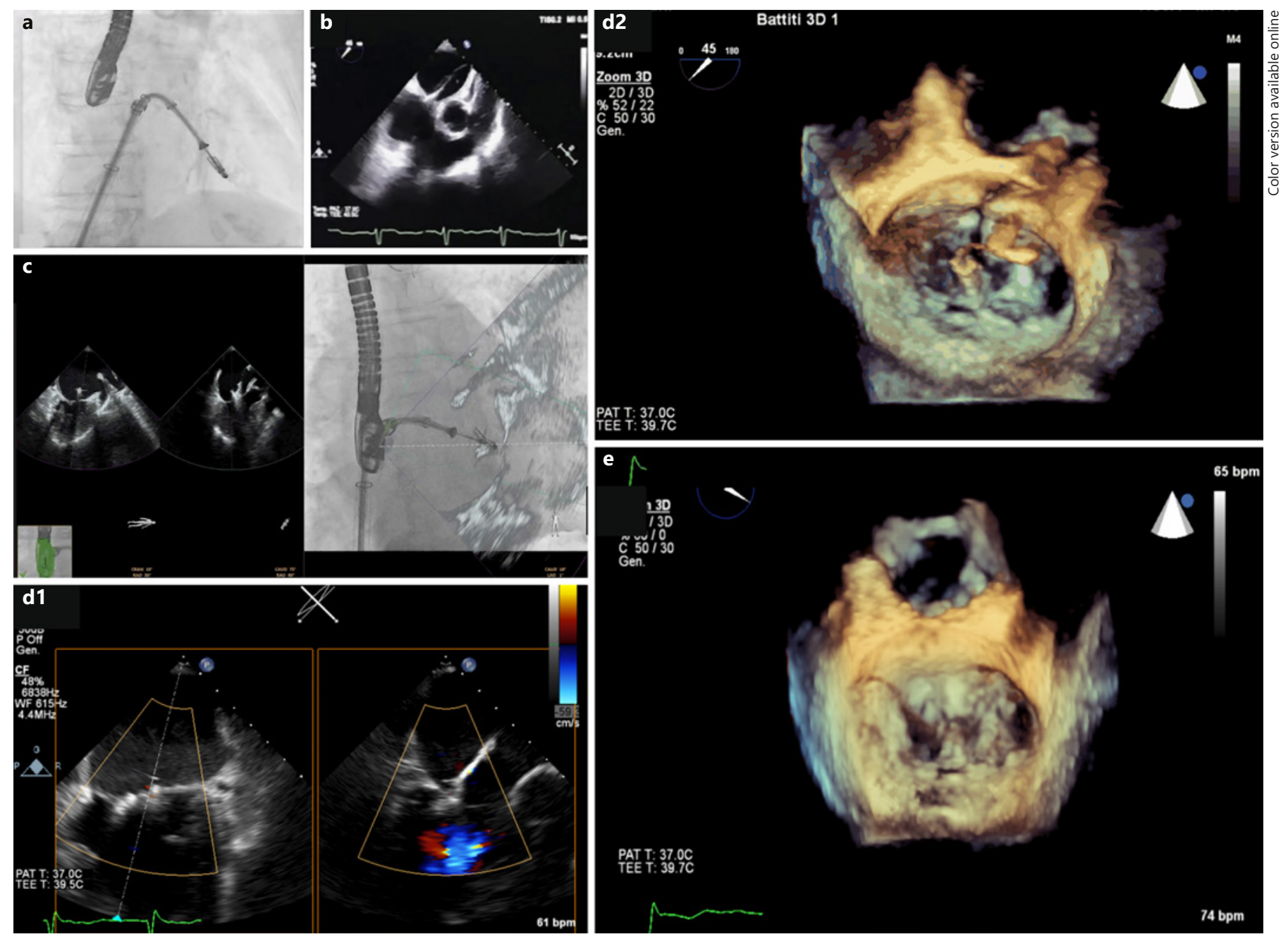

Fig. 4. Phases of MitraClip Proecedures. a Fluoroscopy after transeptal puncture. b TEE after transeptal puncture. c Fusion imaging fluoroscopy/TEE MitraClip navigation. d1 Leaflet's grasping (X plane). d2 Leaflet's grasping (3D TEE). e Final result (3D TEE). TEE, transesophageal echocardiogram.

zation of the balloon, the heart needs to be fully empty and not ejecting: the TEE images of aortic valve leaflet not opening during systole are useful and easily accessible. During balloon inflation and cardioplegia delivering, the correct position and perfect adherence of the device to the aortic wall and the degree of aortic regurgitation is revealed by a good TEE view (long axis view of ascending aorta at $120^{\circ}$ ). Even for occlusion of the aorta using a more conventional trans-thoracic external clamp, echo images are crucial to assess the correct delivering of cardioplegia into aortic root and lack of distortion of aortic leaflets due to the clamp. In both ways, to occlude the aorta, an accurate view of intracoronary flow is realized by TEE.

Echocardiography and Correction of MR: An Unbreakable Link
Appropriate de-airing at the end of the procedure is a critical step of operation with minimal access with respect to conventional mitral operation, to avoid cerebral or coronary embolism. An accurate visualization of the left chambers of the heart by TEE is mandatory with respect to conventional surgery where the surgeon can adopt specific maneuvers to "clean" the heart.

\section{Percutaneous Edge-to-Edge MV Repair with \\ MitraClip System}

The MitraClip device has evolved as a promising interventional tool for MV repair in severe MR [8-39]. The first randomized controlled study (endovascular valve edge-to-edge repair; EVEREST II) demonstrated 
Table 3. MV suitability criteria for MitraClip intervention

\begin{tabular}{|c|c|c|c|}
\hline & Ideal MV morphology & $\begin{array}{l}\text { "Conditionally suitable" MV } \\
\text { morphology }\end{array}$ & Unsuitable MV morphology \\
\hline MR origin & $\begin{array}{l}\text { Mid portion of MV (either } \\
\text { primary or secondary etiology) }\end{array}$ & $\begin{array}{l}\text { Segment } 1 \text { or } 3 \text { (either } \\
\text { leaflets) }\end{array}$ & \\
\hline Leaflet characteristics & $\begin{array}{l}\text { No calcification in grasping } \\
\text { area }\end{array}$ & $\begin{array}{l}\text { Mild calcification OUTSIDE } \\
\text { grasping area }\end{array}$ & $\begin{array}{l}\text { Heavy calcification in grasping area, } \\
\text { cleft, perforation, rigidity, extensive } \\
\text { thickening of leaflets (Barlow) }\end{array}$ \\
\hline $\mathrm{MV}$ area, $\mathrm{cm}^{2}$ & $>4$ & $3-4$ & $<3$ \\
\hline Length of PL, mm & $\geq 10$ & $\geq 6-7$ & $<6$ \\
\hline Type of MV disease & $\begin{array}{l}\text { No rheumatic } \\
\text { No endocarditis }\end{array}$ & & $\begin{array}{l}\text { Rheumatic, with significant } \\
\text { mitral stenosis }\end{array}$ \\
\hline Coaptation length, $\mathrm{mm}$ & $>2$ & & \\
\hline
\end{tabular}

superior safety to surgical MV repair/replacement accompanied by inferior clinical efficacy but similar improvements in clinical outcome $[40,41]$. The procedure is performed under general anesthesia, TEE-guided, with $2 \mathrm{D} / 3 \mathrm{D}$ probe. TEE plays a key role in the procedure by providing information regarding clip navigation inside left chambers, clip alignment to the MV coaptation line, the advancement of the system through the $\mathrm{MV}$, leaflet grasping, validation of valve tissue catching and assessment of the result. TEE is also crucial during the trans-septal puncture, which should be superior and posterior to facilitate steering maneuvers. RT3D TEE has increasing value in Mitraclip intervention providing high-quality visualization of both the heart and the intravascular devices. With X-Plane function is possible to have, at the same time, one view and its orthogonal, to orientate in both antero-posterior and latero-medial directions. Recently a new system called "heart navigator" has been developed, which integrates fluoroscopy and echography to improve trans-catheter MV repair guidance [42]. Figure 4 shows main phases of MitraClip intervention. In contrast to MV surgery, where TEE is involved only in the pre-surgical assessment phase and in results evaluation, TEE is mandatory to guide management during MitraClip repair. In the screening phase, TEE is useful to exclude the presence of any contraindication for transeptal puncture (e.g.,
Patent Foramen Ovalis or Atrial Septal Defect). TEE is also mandatory to assess anatomic characteristics of the valve that would make Mitra-Clip implantation unlikely or not suitable according to the EVEREST criteria [8-40] (e.g., the presence of leaflet calcification in grasping area, the rigidity of leaflets with a little MV area $<3$ $\mathrm{cm}^{2}$, a very short PL, the presence of cleft or perforations). Table 3 shows ideal and unfavorable MV characteristics for Mitra-Clip implantation. Percutaneous MV repair is actually indicated in both primary and secondary MR [6] and seems to be less effective in patients with severely dilated LV and end-stage heart failure [43-47].

\section{Transcatheter Direct Annuloplasty with Cardioband System}

The Cardioband ${ }^{\circledR}$ system (Valtech Cardio, Edwards Lifescience) is a transcatheter direct annuloplasty device that reproduces surgical annuloplasty. The device is tailored to reduce the MV annulus and minimize MR and it is delivered through a venous femoral puncture and a 25 Fr trans-septal steerable sheath and then implanted in the beating heart over the posterior side of the MV annulus under fluoroscopic and TEE echocardiographic guidance. TEE plays a key role, as in MitraClip procedure, from the screening phase to the procedural guidance and results evaluation. The implant size has to be decided 
based on the length of the posterior annulus (from trigone to trigone) at mid diastole measured by both TEE and CT scan [48].

\section{Conclusions}

In summary, both TTE and TEE echocardiography have a crucial role in the decisional process and the guidance of MV repair procedures. TTE is the main investiga- tion and the first approach used to make diagnosis of MR, to assess the severity and to describe the underlying mechanism, while TEE, especially with 3D echocardiography, has been shown to be useful for clarifying complicated valvular anatomy, assessing the surgical result and detecting complications. The surgical treatment of MR takes advantage of ultrasound evaluation of MV apparatus at any stage of the process, thus making the link between surgery and unbreakable throughout the perioperative phase.

\section{References}

1 Carpentier A, Chauvaud S, Fabiani JN, Deloche A, Relland J, Lessana A, et al. Reconstructive surgery of mitral valve incompetence: ten-year appraisal. J Thorac Cardiovasc Surg. 1980 Mar;79(3):338-48.

2 Rossi A, Dini FL, Faggiano P, Agricola E, Cicoira M, Frattini S, et al. Independent prognostic value of functional mitral regurgitation in patients with heart failure. A quantitative analysis of 1256 patients with ischaemic and non-ischaemic dilated cardiomyopathy. Heart. 2011 Oct;97(20): 1675-80.

3 Trichon BH, Felker GM, Shaw LK, Cabell CH, O'Connor CM. Relation of frequency and severity of mitral regurgitation to survival among patients with left ventricular systolic dysfunction and heart failure. Am J Cardiol. 2003 Mar;91(5):538-43.

4 Lancellotti P, Tribouilloy C, Hagendorff A, Popescu BA, Edvardsen T, Pierard LA, et al.; Scientific Document Committee of the European Association of Cardiovascular Imaging. Recommendations for the echocardiographic assessment of native valvular regurgitation: an executive summary from the European Association of Cardiovascular Imaging. Eur Heart J Cardiovasc Imaging. 2013 Jul;14(7):611-44.

5 de Marchena E, Badiye A, Robalino G, Junttila J, Atapattu S, Nakamura M, et al. Respective prevalence of the different carpentier classes of mitral regurgitation: a stepping stone for future therapeutic research and development. J Card Surg. 2011 Jul;26(4):385-92.

6 Baumgartner H, Falk V, Bax JJ, De Bonis M, Hamm C, Holm PJ, et al.; ESC Scientific Document Group. 2017 ESC/EACTS Guidelines for the management of valvular heart disease. Eur Heart J. 2017 Sep;38(36):2739-91.

7 Ponikowski P, Voors AA, Anker SD, Bueno H, Cleland JG, Coats AJ, et al.; Authors/ Task Force Members; Document Reviewers. 2016 ESC Guidelines for the diagnosis and treatment of acute and chronic heart failure: the Task Force for the diagnosis and treatment of acute and chronic heart failure of the European Society of Cardiology (ESC). Developed with the special contribution of the Heart Failure Association (HFA) of the ESC. Eur J Heart Fail. 2016 Aug; 18(8): 891-975.

8 Feldman T, Kar S, Rinaldi M, Fail P, Hermiller J, Smalling R, et al.; EVEREST Investigators. Percutaneous mitral repair with the MitraClip system: safety and midterm durability in the initial EVEREST (Endovascular Valve Edge-to-Edge REpair Study) cohort. J Am Coll Cardiol. 2009 Aug;54(8):686-94.

9 Varghese R, Itagaki S, Anyanwu AC, Milla F, Adams DH. Predicting early left ventricular dysfunction after mitral valve reconstruction: the effect of atrial fibrillation and pulmonary hypertension. J Thorac Cardiovasc Surg. 2014 Aug;148(2):422-7.

10 Murashita T, Okada Y, Kanemitsu H, Fukunaga N, Konishi Y, Nakamura K, et al. The impact of preoperative and postoperative pulmonary hypertension on long-term surgical outcome after mitral valve repair for degenerative mitral regurgitation. Ann Thorac Cardiovasc Surg. 2015;21(1):53-8.

11 Lang RM, Badano LP, Mor-Avi V, Afilalo J, Armstrong A, Ernande L, et al. Recommendations for cardiac chamber quantification by echocardiography in adults: an update from the American Society of Echocardiography and the European Association of Cardiovascular Imaging. J Am Soc Echocardiogr. 2015 Jan;28(1):1-39.e14

12 Monaghan MJ. Role of real time 3D echocardiography in evaluating the left ventricle. Heart. 2006 Jan;92(1):131-6.

13 Tsang W, Salgo IS, Medvedofsky D, Takeuchi M, Prater D, Weinert L, et al . Transthoracic 3D Echocardiographic Left Heart Chamber Quantification Using an Automated Adaptive Analytics Algorithm. JACC Cardiovasc Imaging. 2016 Jul;9(7):769-82.

14 Medvedofsky D, Mor-Avi V, Amzulescu M, Fernández-Golfín C, Hinojar R, Monaghan $\mathrm{MJ}$, et al. Three-dimensional echocardiographic quantification of the left-heart chambers using an automated adaptive analytics algorithm: multicentre validation study. Eur Heart J Cardiovasc Imaging. 2018 Jan;19(1):47-58.

15 Colombo T, Russo C, Ciliberto GR, Lanfranconi M, Bruschi G, Agati S, et al. Tricuspid regurgitation secondary to mitral valve dis- ease: tricuspid annulus function as guide to tricuspid valve repair. Cardiovasc Surg. 2001 Aug;9(4):369-77.

16 Matsunaga A, Duran CM. Progression of tricuspid regurgitation after repaired functional ischemic mitral regurgitation. Circulation. 2005 Aug;112(9 Suppl):I453-7.

17 Rudski LG, Lai WW, Afilalo J, Hua L, Handschumacher MD, Chandrasekaran $\mathrm{K}$, et al. Guidelines for the echocardiographic assessment of the right heart in adults: a report from the American Society of Echocardiography endorsed by the European Association of Echocardiography, a registered branch of the European Society of Cardiology, and the Canadian Society of Echocardiography. J Am Soc Echocardiogr. 2010 Jul;23(7):685-713.

18 Hahn RT, Abraham T, Adams MS, Bruce CJ, Glas KE, Lang RM, et al. Guidelines for performing a comprehensive transesophageal echocardiographic examination: recommendations from the American Society of Echocardiography and the Society of Cardiovascular Anesthesiologists. J Am Soc Echocardiogr. 2013 Sep;26(9):921-64.

19 Foster GP, Isselbacher EM, Rose GA, Torchiana DF, Akins CW, Picard MH. Accurate localization of mitral regurgitant defects using multiplane transesophageal echocardiography. Ann Thorac Surg. 1998 Apr;65(4):102531.

20 Enriquez-Sarano M, Freeman WK, Tribouilloy CM, Orszulak TA, Khandheria BK, Seward JB, et al. Functional anatomy of mitral regurgitation: accuracy and outcome implications of transesophageal echocardiography. J Am Coll Cardiol. 1999 Oct;34(4):1129-36.

21 Grewal KS, Malkowski MJ, Kramer CM, Dianzumba S, Reichek N. Multiplane transesophageal echocardiographic identification of the involved scallop in patients with flail mitral valve leaflet: intraoperative correlation. J Am Soc Echocardiogr. 1998 Oct;11(10):966-71.

22 Chauvel C, Bogino E, Clerc P, Fernandez G, Vernhet JC, Becat A, et al. Usefulness of threedimensional echocardiography for the evaluation of mitral valve prolapse: an intraoperative study. J Heart Valve Dis. 2000 May;9(3): 341-9. 
23 Hozumi T, Yoshikawa J, Yoshida K, Akasaka T, Takagi T, Yamamuro A. Assessment of flail mitral leaflets by dynamic three-dimensional echocardiographic imaging. Am J Cardiol. 1997 Jan;79(2):223-5.

24 Salustri A, Becker AE, van Herwerden L, Vletter WB, Ten Cate FJ, Roelandt JR. Three-dimensional echocardiography of normal and pathologic mitral valve: a comparison with two-dimensional transesophageal echocardiography. J Am Coll Cardiol. 1996 May; 27(6):1502-10.

25 Carpentier AF, Lessana A, Relland JY, Belli E, Mihaileanu S, Berrebi AJ, et al. The "physioring": an advanced concept in mitral valve annuloplasty. Ann Thorac Surg. 1995 Nov; 60(5):1177-85.

26 Tsang W, Lang RM. Three-dimensional echocardiography is essential for intraoperative assessment of mitral regurgitation. Circulation. 2013 Aug;128(6):643-52.

27 Garbi M, Monaghan MJ. Quantitative mitral valve anatomy and pathology. Echo Res Pract. 2015 Sep;2(3):R63-72.

28 Chikwe J, Adams DH, Su KN, Anyanwu AC, Lin $\mathrm{HM}$, Goldstone $\mathrm{AB}$, et al. Can threedimensional echocardiography accurately predict complexity of mitral valve repair? Eur J Cardiothorac Surg. 2012 Mar;41(3): 518-24.

29 Varghese R, Itagaki S, Anyanwu AC, Trigo P, Fischer G, Adams DH. Predicting systolic anterior motion after mitral valve reconstruction: using intraoperative transoesophageal echocardiography to identify those at greatest risk. Eur J Cardiothorac Surg. 2014 Jan;45(1): 132-7.

30 Berrebi A. [Mitral valve repair: echocardiography is its best friend]. Rev Esp Cardiol. 2011 Jul;64(7):554-6.

31 Kang DH, Kim MJ, Kang SJ, Song JM, Song $\mathrm{H}$, Hong $\mathrm{MK}$, et al. Mitral valve repair versus revascularization alone in the treatment of ischemic mitral regurgitation. Circulation. 2006 Jul;114(1 Suppl):I499-503.
32 Ruvolo G, Speziale G, Bianchini R, Greco E, Tonelli E, Marino B. Combined coronary bypass grafting and mitral valve surgery: early and late results. Thorac Cardiovasc Surg. 1995 Apr;43(2):90-3.

33 Ciarka A, Braun J, Delgado V, Versteegh M, Boersma E, Klautz R, et al. Predictors of mitral regurgitation recurrence in patients with heart failure undergoing mitral valve annuloplasty. Am J Cardiol. 2010 Aug;106(3):395401.

34 Casselman F, Aramendi J, Bentala M, Candolfi P, Coppoolse R, Gersak B, et al. Endoaortic clamping does not increase the risk of stroke in minimal access mitral valve surgery: A multicenter experience. Ann Thorac Surg. 2015 Oct;100(4):1334-9.

35 Marullo AG, Irace FG, Vitulli P, Peruzzi M, Rose D, D'Ascoli R, et al. Recent Developments in Minimally Invasive Cardiac Surgery: evolution or Revolution? BioMed Res Int. 2015;2015:483025.

36 Silbiger JJ. Mechanistic insights into ischemic mitral regurgitation: echocardiographic and surgical implications. J Am Soc Echocardiogr. 2011 Jul;24(7):707-19.

37 Greco E, Zaballos JM, Alvarez L, Urso S, Pulitani I, Sàdaba R, et al. Video-assisted mitral surgery through a micro-access: a safe and reliable reality in the current era. J Heart Valve Dis. 2008 Jan; 17(1):48-53.

38 Greco E, Rose D, Irace F, Frati G. Optimizing the exposure in minimally invasive mitral surgery: a new left atrial retractor system. J Thorac Dis. 2016 Dec;8(12):3728-32.

39 Feldman T, Foster E, Glower DD, Kar S, Rinaldi MJ, Fail PS, et al.; EVEREST II Investigators. Percutaneous repair or surgery for mitral regurgitation. N Engl J Med. 2011 Apr; 364(15):1395-406.

40 Tamburino C, Ussia GP, Maisano F, Capodanno D, La Canna G, Scandura S, et al. Percutaneous mitral valve repair with the MitraClip system: acute results from a real world setting. Eur Heart J. 2010 Jun;31(11): $1382-9$
41 Feldman T, Foster E, Glower DD, Kar S, Rinaldi MJ, Fail PS, et al.; EVEREST II Investigators. Percutaneous repair or surgery for mitral regurgitation. N Engl J Med. 2011 Apr; 364(15):1395-406.

42 Whitlow PL, Feldman T, Pedersen WR, Lim DS, Kipperman R, Smalling R, et al.; EVEREST II Investigators. Acute and 12-month results with catheter-based mitral valve leaflet repair: the EVEREST II (Endovascular Valve Edge-to-Edge Repair) High Risk Study. J Am Coll Cardiol. 2012 Jan;59(2):130-9.

43 Faletra FF, Pozzoli A, Agricola E, Guidotti A, Biasco L, Leo LA, et al. Echocardiographicfluoroscopic fusion imaging for transcatheter mitral valve repair guidance. Eur Heart J Cardiovasc Imaging. 2018 Jul;19(7):715-26.

44 Scandura S, Ussia GP, Capranzano P, Caggegi A, Sarkar K, Cammalleri V, et al. Left cardiac chambers reverse remodeling after percutaneous mitral valve repair with the MitraClip system. J Am Soc Echocardiogr. 2012 Oct; 25(10):1099-105.

45 Rammos C, Zeus T, Balzer J, Veulemans V, Hellhammer K, Niebel S, et al. Left Atrial and Left Ventricular Function and Remodeling Following Percutaneous Mitral Valve Repair. J Heart Valve Dis. 2016 May;25(3):309-19.

46 Cimino S, Maestrini V, Cantisani D, Petronilli V, Filomena D, Mancone M, et al. 2D/3D echocardiographic determinants of left ventricular reverse remodelling after MitraClip implantation. Eur Heart J Cardiovasc Imaging. 2019 May;20(5):558-64.

47 Cimino S, Maestrini V, Cantisani D, Petronilli V, Filomena D, Mancone M, et al. Midterm repair durability after MitraClip implantation in patients with functional mitral regurgitation. J Cardiovasc Med (Hagerstown). 2019 Oct;20(10):701-8.

48 Messika-Zeitoun D, Nickenig G, Latib A, Kuck $\mathrm{KH}$, Baldus S, Schueler R, et al. Transcatheter mitral valve repair for functional mitral regurgitation using the Cardioband system: 1 year outcomes. Eur Heart J. 2019 Feb;40(5):466-72. 